\title{
The Impact of Excessive Cytokine Production in the Body, Particularly in the Context of Virus Infection
}

\author{
Heba N Gad EL Hak* \\ Department of Zoology, Suez Canal University, Egypt \\ *Corresponding author: Heba N Gad EL Hak, Department of Zoology, Suez Canal University, Egypt
}

\section{ARTICLE INFO}

Received: 㓞 June 24, 2020

Published: 幽 July 08, 2020

Citation: Heba N Gad EL Hak. The Impact of Excessive Cytokine Production in the Body, Particularly in the Context of Virus Infection. Biomed J Sci \& Tech Res 28(4)2020. BJSTR. MS.ID.004698.
ABSTRACT

The present review attempted to summarize the results of studies that examined the effects of overreaction on cytokines in the body with an emphasis on their effects on popular viruses. In general, most of the studies reviewed suggested beneficial effects of cytokines on the improvement of the immune system by increasing the expression of anti-inflammatory cytokines while reducing the expression of proinflammatory cytokines. The purpose of the present review is to briefly describe the impact of excessive cytokine production in the body, particularly in the context of virus infection.

Keywords: Cytokines; Virus Disease; Covid-19; SARS; Immune system

\section{Mini Review}

SARS -CoV-2; covid-19 and multiple influenza forms such as H5N1 influenza virus can be lethal to humans due to an overreaction of the body's immune system called a cytokine storm [1]. The term 'cytokine' arises from the Greek words for cell (cyto) and movement (kinos) [2]. Cytokines are small molecular proteins that express the need for various parts of the immune system to take action to organize the response of the body to infection and induce inflammation [3]. Inflammatory signs include redness (increased blood flow), swelling, pain and increased temperature [4]. Cytokines released act by binding receptors located either in neighboring cells or even in the same cell that released them [5]. Some cytokines can stimulate further cytokine release, create a positive feedback loop and intensify the inflammation. This often results in fever, a key inflammatory condition [6]. Cytokines include chemokines that cause immune system cells to transfer to a certain location; interferons that are central to antiviral defense and named for their ability to "interfere" with viral replication; lymphokines generated by immune system cells known as lymphocytes; and tumor necrosis factors named after their ability to destroy tumor cells [7]. Such reviews have attempted to synthesize the available knowledge and to concentrate on information on the response of the body to SARS virus infection and to assess the damage can be caused by the overreaction of cytokine, particularly seen in Covid 19.

\section{The body's Response to Virus Infection}

Sometimes the body's response to infection can go into overdrive. Viral infections of tissues with high renewal rates, such as epithelium, resulting in the development of Type-I IFNs (IFN- $\alpha$ and IFN- $\beta$ ), which induce the expression of more than 200 antiviral genes capable of interfering with multiple stages of the cycles of viral infection and sensitizing infected cells to cytotoxic NK cells and CD8 + T cells [8]. Type I IFNs also promote cytotoxic activity of $\mathrm{NK}$ and CD8 + T cells and induce an antiviral state in adjacent cells [9]. Importantly, any of the viral pathogen sensors will induce all of these responses as their signaling pathways converge on IRF3 and/ or 7 activation and type IFN output [10]. There is a major difference between IFN induction by cell-intrinsic sensors such as RLRs and cytosolic DNA sensors and TLR3, TLR7, TLR8 and TLR9-mediated cell-extrinsic mechanisms. Cell-intrinsic sensors are omnipresent and activate the development of IFN- $\beta$ in infected cells, while TLRs involved in viral recognition are expressed in specialized cells, such as plasmacytoid dendritic cells (pDCs), which produce large amounts of IFN- $\alpha$ in infected tissues. Host protection strategy 
against viral infections is to interfere with viral replication and spread and to destroyed infected cells, often with the aid of cytotoxic lymphocytes (NK cells and CD8+ T cells) [8].

The virus that causing SARS (Severe Acute Respiratory Syndrome) is a novel member of the coronavirus family. Coronaviruses are single-stranded RNA viruses with asymmetric structure and surface spikes located in such a way that they resemble a crown. Most human coronaviruses relate only to mild respiratory disease. Thus, in early 2003, the world was caught off guard by the incidence of atypical pneumonia caused by the newly emerging Coronavirus SARS. In this initial outbreak, more than 8000 cases of infection that resulted in more than 700 deaths were reported. Scientists speculate that the SARS virus may have arisen in a sudden species jump from healthy civet cats to their owners in China in late 2002. Symptoms of SARS are flu-like and include fever, chills, malaise, dry cough, shortness of breath, and headache. There are also liver damage and lymphopenia. When SARS -CoV2 - the virus behind the covid-19 pandemic enters the lungs, it causes an immune response, attracting immune cells to the region to combat the virus, leading to localized inflammation. But in some patients, however, excessive or uncontrolled levels of cytokines are released which then activate more immune cells, leading to hyperinflammation. This can seriously harm or even kill the patient with progressive damage to the alveoli of the lungs. The virus spreads among humans through close contact, such as touching a contaminated surface or breathing in aerosol droplets produced by the coughing or sneezing of an infected person. At the cellular level the SARS virus replicates primarily in respiratory epithelial cells, although other tissues (such as eyes, heart, liver, kidneys) and other types of cell such as macrophages that may also be targeted [11].

Despite having recorded more than 200,000 deaths worldwide, scientists are only just beginning to understand the effect COVID-19 on the body. The virus not only affects the lungs and respiratory system but also induces cardiovascular, gastrointestinal, and neurological symptoms [12]. The fatal cases of COVID-19 result from a person's immune system with overactivated with excessive or uncontrolled cytokine levels [13]. Fanos, Pintus [14] and Zhang, Guo [15] found in COVID-19 patients considerable increase of cytokines with the migration and activation of macrophages with inducing inflammation that can migrate to the lungs resulting in respiratory failure. The possibility that a cytokine overreaction and out of control contributes to the severe disease state and death of COVID-19 originally emerged from a report of Mehta, McAuley [16]. Excessive or uncontrolled cytokine levels are not only a common complication of covid-19 and flu, but also of other respiratory diseases induced by coronaviruses such as SARS and MERS. These also contribute to non-infectious diseases including multiple sclerosis and pancreatitis [17]. In many of these patients, excessive cytokines have induced severe acute respiratory distress syndrome, where the lungs are unable to supply adequate the body's vital organs with oxygen [18,19].
The phenomenon of excessive or uncontrolled cytokine rates became more widely known following the 2005 outbreak of the avian H5N1 influenza virus "bird flu", when correlate the high mortality rate was linked to an out of control cytokine response [20]. Suntharalingam, Perry [21] found in six healthy volunteer men were left in intensive care with multiple organ failure most notably early acute lung injury and marked lymphopenia after 90 minutes of received a new kind of drug as a result of an out of control cytokine immune response during a preclinical trial. Excessive or uncontrolled cytokine levels can explain the reason of some people have a serious coronavirus reaction while others suffer of only mild symptoms. They may also be the reason why younger people are less affected, since their immune systems are less evolved and thus produce lower rates of inflammation-driving cytokines [22].

\section{Suggested Treatment for SARS -CoV-2; covid-19 and Multiple Influenza Virus Attack}

Cytokines are host response regulators for virus infections, immune reactions, inflammation and trauma [23]. Some cytokines work to make injury worse (proinflammatory), while others work to decrease inflammation and facilitate healing (anti-inflammatory) [3]. Treatment may be suggested by reducing the biological activity of interleukin (IL)-1, IL-18 and Tumor Necrosis Factor (TNF) cytokines that are harmful to the host, especially during an overwhelming infection [24]. Reducing the biological activity of IL-1 and TNF is achieved through various, but highly specific, strategies involving neutralizing antibodies, soluble receptors, receptor antagonists, and protease inhibitors that convert inactive precursors into active, mature molecules [25]. IL-1 or TNF blockage has been very effective in patients with rheumatoid arthritis, inflammatory intestinal disease or graft-vs-host disease [3]. Oettinger, D'Souza [26] and Ulloa and Tracey [27] found in animal studies the cytokine neutralisation could prevent development of septic shock. Zhang, Gharaee-Kermani [28] found decrease cytokine may decrease the lung fibrosis. Kurokawa, Watanabe [29] suggested to suppress pneumonia induced in influenza virus infected mice by suppression of the cytokine produced by that virus [30]. Chen and Subbarao [30] found blocking the TNF $\alpha$ with a specific antibody In SARS-infected mice make them unable to respond to type 1 interferon, protect them from severe lung pathology and allows them to survive even after infection with an otherwise a mortality dose of the virus. In future, Ant cytokine therapy may be investigated with an infected patient with SARS -CoV-2; covid-19 and multiple influenza virus in control strategies may rescue the patient from death. The control strategy for not suffering the patient with reduction and functional decline in key immune cells.

\section{Conclusion}

Treatments look to use Ant cytokine therapy by reducing the activation of immune cells by interfering with cytokine production or blocking specific signalling pathways dependent on proinflammatory cytokines may be able to rescue the patient of SARS 
-CoV-2; Covid-19 and multiple influenza virus. Unfortunately, it remains difficult to identify those patients who would benefit from ant cytokine therapy. Further clinical and immunological analysis of severe COVID-19 cases is necessary for better understanding this infection and identifying the best therapy.

\section{References}

1. Yi Y, Lagniton PNP, Ye S, Li E, Xu R H (2020) COVID-19: what has been learned and to be learned about the novel coronavirus disease. International journal of biological sciences 16(10): 1753-1766.

2. Kaur G, Mehra N (2012) Cytokine Gene Polymorphisms: Methods of Detection and Biological Significance. Methods and Applications in Clinical Practice 882: 549-568.

3. Dinarello CA (2000) Proinflammatory Cytokines. Chest 118(2): 503508.

4. Huygen FJ, De Bruijn AG, De Bruin MT, Groeneweg JG, Klein J (2002) Evidence for local inflammation in complex regional pain syndrome type 1. Mediators of inflammation 11(1): 47-51.

5. Zitvogel L, Kepp O, Kroemer G (2010) Decoding cell death signals in inflammation and immunity. Cell 140(6): 798-804.

6. Blackwell TS, Christman JW (1997) The role of nuclear factor- $\kappa$ B in cytokine gene regulation. American journal of respiratory cell and molecular biology 17(1): 3-9.

7. Moser M, Leo O (2010) Key concepts in immunology. Vaccine 28(3): C2C13.

8. Nish S, Medzhitov R (2011) Host Defense Pathways: Role of Redundancy and Compensation in Infectious Disease Phenotypes. Immunity 34(5): 629-236.

9. Stetson DB, Medzhitov R (2006) Type I interferons in host defense. Immunity 25(3): 373-381.

10. Honda K, Taniguchi T (2006) IRFs: master regulators of signalling by Toll-like receptors and cytosolic pattern-recognition receptors. Nature Reviews Immunology 6(9): 644-658.

11. Mak TW, Saunders ME (2006) Immunity to Pathogens. The Immune Response 641-694.

12. Wimalawansa SJ (2020) Global Epidemic of Coronavirus-Covid-19: What Can We Do to Minimize Risks. European Journal of Biomedical 7: 432-438.

13. Cao YC, Deng QX, Dai SX (2020) Remdesivir for severe acute respiratory syndrome coronavirus 2 causing COVID-19: An evaluation of the evidence. Travel Medicine and Infectious Disease 35:101647.

14. Fanos V, Pintus MC, Pintus R, Marcialis MA (2020) Lung microbiota in the acute respiratory disease: from coronavirus to metabolomics. Journal of Pediatric and Neonatal Individualized Medicine (JPNIM).

15. Zhang D, Guo R, Lei L, Liu H, Wang Y, et al. (2020) COVID-19 infection induces readily detectable morphological and inflammation-related

ISSN: 2574-1241

DOI: $10.26717 /$ BJSTR.2020.28.004698

Heba N Gad EL Hak. Biomed J Sci \& Tech Res

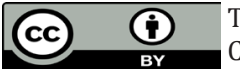

This work is licensed under Creative Commons Attribution 4.0 License

Submission Link: https://biomedres.us/submit-manuscript.php phenotypic changes in peripheral blood monocytes, the severity of which correlate with patient outcome. medRxiv.

16. Mehta P, Mc Auley DF, Brown M, Sanchez E, Tattersall RS, et al. (2020) COVID-19: consider cytokine storm syndromes and immunosuppression. The Lancet 395: 1033-1034.

17. Prompetchara E, Ketloy C, Palaga T (2020) Immune responses in COVID-19 and potential vaccines: Lessons learned from SARS and MERS epidemic. Asian Pac J Allergy Immunol 38(1): 1-9.

18. Brenner T, Motsch J, Werner J, Grenacher L, Martin E, et al. (2010) Rapid-onset acute respiratory distress syndrome (ARDS) in a patient undergoing metastatic liver resection: a case report and review of the literature. Anesthesiology research and practice 2010.

19. Gu J, Korteweg C (2007) Pathology and pathogenesis of severe acute respiratory syndrome. The American journal of pathology 170(4): 11361147.

20. Ignatova KD (2007) Myths, Metaphors, and Mass-Mediated Reality: US Press Coverage of Bird Flu and Avian Influenza Pandemic, 1996-2006. University of Tennessee.

21. Suntharalingam G, Perry MR, Ward S, Brett SJ, Castello-Cortes A, et al (2006) Cytokine storm in a phase 1 trial of the anti-CD28 monoclonal antibody TGN1412. New England Journal of Medicine 355: 1018-1028.

22. Rouse BT, Sehrawat S (2010) Immunity and immunopathology to viruses: what decides the outcome? Nature Reviews Immunology 10(7): 514-526.

23. Hofmann S, Rösen Wolff A, Tsokos G, Hedrich C (2012) Biological properties and regulation of IL-10 related cytokines and their contribution to autoimmune disease and tissue injury. Clinical immunology 143(2): 116-127.

24. Opal SM, De Palo VA (2000) Anti-Inflammatory Cytokines. Chest 117(4): $1162-1172$.

25. Ksontini R, Mac Kay SL, Moldawer LL (1998) Revisiting the role of tumor necrosis factor $\alpha$ and the response to surgical injury and inflammation. Archives of surgery 133(5): 558-567.

26. Oettinger CW, D Souza M, Milton GV (1999) Targeting macrophages with microspheres containing cytokine-neutralizing antibodies prevents lethality in gram-negative peritonitis. Journal of interferon \& cytokine research 19(1): 33-40.

27. Ulloa L, Tracey KJ (2005) The 'cytokine profile': a code for sepsis. Trends in molecular medicine. 11(2): 56-63.

28. Zhang K, Gharaee Kermani M, Mc Garry B, Remick D, Phan SH (1997) TNFalpha-mediated lung cytokine networking and eosinophil recruitment in pulmonary fibrosis. The Journal of Immunology 158(2): 954-959.

29. Kurokawa M, Watanabe W, Shimizu T, Sawamura R, Shiraki K (2010) Modulation of cytokine production by 7-hydroxycoumarin in vitro and its efficacy against influenza infection in mice. Antiviral research 85(2): 373-380.

30. Chen J, Subbarao K (2007) The immunobiology of SARS. Annu Rev Immunol 25: 443-472.

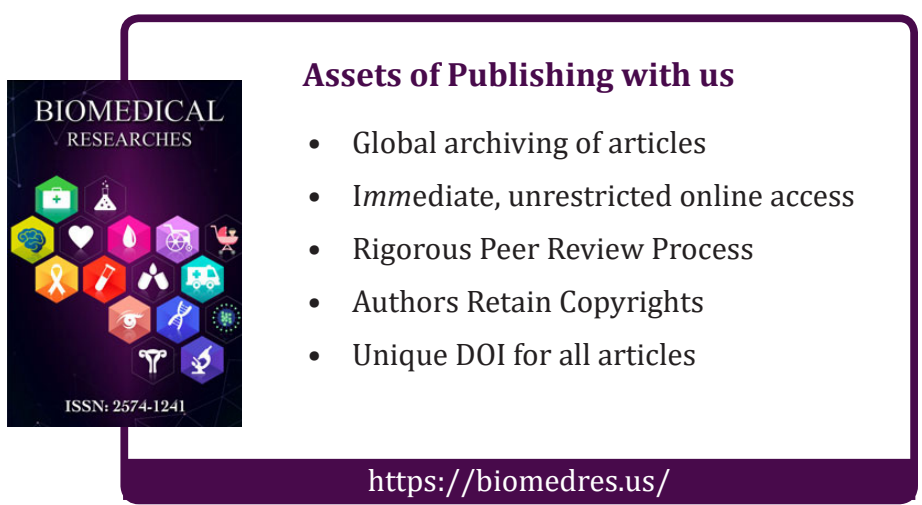

